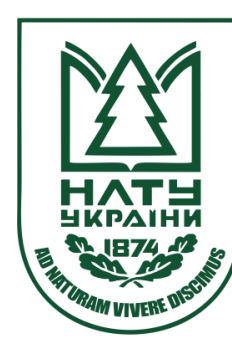

Науковий вісник НЛТУ України Scientific Bulletin of UNFU

https://nv.nltu.edu.ua

https://doi.org/10.15421/40280721

$@ \bowtie$ Correspondence author

Article received 26.07.2018 p.

Article accepted 26.09.2018 p.

R. T. Karpyk

УДК 621.74 .07

karpykroman@gmail.com

Р. Т. Карпик, С. В. Дідик

Івано-Франківський національний технічний університет нафти і газу, м. Івано-Франківськ, Україна

\title{
АВТОМАТИЗАЦІЯ ПРОЦЕСУ ПРОЕКТУВАННЯ ПРЕС-ФОРМ ДЛЯ ЛИТВА ТЕРМОПЛАСТІВ ПІД ТИСКОМ
}

\begin{abstract}
Проаналізовано функції систем автоматизованого проектування за критерієм наявності в одному пакеті можливостей: створювати деталь, проектувати форму для неї, перевіряти їі міцнісні характеристики, симулювати заливання та прогнозувати якість кінцевого виливка. На основі аналізу публікацій показано, що з використанням систем автоматизованого проектування легше проводити стандартизацію й уніфікацію елементів технологічного оснащення та систематизацію проектних рішень, які дають змогу скоротити терміни технологічної підготовки виробництва і зменшити собівартість виробів. На основі створеної моделі деталі у середовищі Autodesk Inventor показано процес розроблення прес-форм для литва із врахуванням технологічних особливостей. Проведено симуляцію заливки з подальшим прогнозом якості виливків, що дає змогу спростити та істотно пришвидшити процеси: проектування прес-форми, здійснення аналізу ливарної порожнини та розроблення керівних програм для оброблення деталей на верстатах з ЧПК. Виконано розрахунки усадок, раціональних температурних параметрів процесу лиття та випробування створених деталей прес-форми на міцність та стійкість із задаванням умов закріплення, взаємного розміщення та навантаження, які діють на модель. У кінцевому підсумку отримано модель прес-форми, 3 яких легко можна зробити кінцеві робочі кресленики всіх деталей.
\end{abstract}

Ключові слова: системи автоматизованого проектування; оснащення; механічні напруження; Autodesk Inventor; підготовка виробництва.

Вступ. На сьогодні у світі дуже велику кількість деталей і виробів виготовляють литтям пластмас, для проведення якого потрібно сконструювати оснащення прес-форму. Для проектування прес-форм чи їхніх деталей використовують CAD-системи (Computer Aided Design), 3 подальшим використанням САМ-систем (Computer Aided Manufacturing), які слугують для технологічної підготовки виробництва. Розрахунок основних деталей та вузлів проводять у САЕ-системах (Computer Aided Engineering) (Glinskih, 2002; Norenkov, 2009; Ryibakov, Evdokimov, \& Meleshina, 2001; Mazein, \& Shalamov, 2002). Проте не всі вони є комплексним інструментом і поєднують в собі можливості створювати деталь, проектувати форму для неї, перевіряти її міцнісні характеристики та симулювати заливання і прогнозувати якість кінцевого виливка. Зазвичай якогось із вказаних вище пунктів у поширених програмах немає, тому завжди доводиться використовувати декілька програмних продуктів, що потребує додаткових затрат на програмне забезпечення. Також під час експорту-імпорту моделей потрібно використовувати файли однакового розширення, що не завжди можливо, окрім цього, файли з перехідним розширенням можуть призводити до неточностей у моделі.

Різного виду систем автоматизованого проектування (САПР) $є$ доволі багато, проте не всі вони $є$ у вільному

доступі для ознайомлення, а їхні інтерфейси є вельми складними, тому для їх використання потрібно як мінімум ознайомитися зі всіма інструкціями виробника програмного продукту. Наявна технічна література та інструкції, що на цей час існують, також не завжди доступні загалу і здебільшого написані англійською мовою, і насичена вузькоспеціалізованою термінологією, яку важко коректно перекласти, а тому потребує багато часу для вивчення. Одним із найбільш доступних і пристосованих для проектування прес-форм для литва пластикових деталей $є$ програмний комплекс Autodesk Inventor.

Аналіз останніх досліджень та публікацій. Сучасне виробництво характеризується багатою номенклатурою виготовлюваних деталей, з великою зміною виробів, що випускаються. При цьому САПР стали невід'ємною частиною виробничого процесу та актуальним напрямом вдосконалення технологічної підготовки виробництва, що забезпечує високу якість та ефективність проектування (Ryibakov, Evdokimov \& Meleshina, 2001; Mazein \& Shalamov, 2002). Розроблення та вдосконалення системи автоматизованого проектування технологічного оснащення дає змогу скоротити терміни технологічної підготовки виробництва і зменшити собівартість виробів, що випускаються (Suberlyak \& Bashtannik, 2007; Vlasov et al., 2004; Melloy et al., 2006;

Інформація про авторів:

Карпик Роман Тимофійович, канд. техн. наук, доцент, кафедра комп'ютеризованого машинобудівного виробництва. Email: karpykroman@gmail.com

Дідик Сергій Вікторович, магістр, кафедра комп'ютеризованого машинобудівного виробництва. Email: didyksergiy2@gmail.com Цитування за ДСту: Карпик Р. Т., Дідик С. В. Автоматизація процесу проектування прес-форм для литва термопластів під тиском. Науковий вісник НЛТУ України. 2018, т. 28, № 7. С. 97-100.

Citation APA: Karpyk, R. T., \& Didyk, S. V. (2018). Automation of process of designing press forms for casting of thermoplasts under pressure. Scientific Bulletin of UNFU, 28(7), 97-100. https://doi.org/10.15421/40280721 
Bekker et al., 1990).

Основою автоматизації процесу проектування технологічного оснащення (пристосувань, штампів, пресформ тощо) є максимальна стандартизація і уніфікація їх елементів та систематизація проектних рішень (Vidgof, 1979; Mirzgoev et al., 1972).

Метою роботи є демонстрація технологічних можливостей САПР Autodesk Inventor для створення моделей пластикових деталей та проектування прес-форм, для їх лиття, на базі цих моделей із подальшим випробовуванням елементів прес-форми, перевірки та аналізу кінцевого виливка на предмет якості та відповідності усім вимогам.

Обгрунтування автоматизації процесу проектування прес-форм для виготовлення литтям деталей із термопластів у Autodesk Inventor. Метою автоматизації проектних робіт $є$ насамперед скорочення тривалості проектування та зменшення витрат на проектування. Це дає змогу зменшити час на проектування та випробування розробленого оснащення ще на стадії підготовки виробництва. Загалом процес проектування можна охарактеризувати такими кроками (рис. 1).

\begin{tabular}{|c|c|c|c|}
\hline Параметризована & Створення шаблону & Підбір кількості та & Створення ливниковоі \\
\hline модель деталі & матрці та пуансона & розмішення гнізд у формі & системи \\
\hline
\end{tabular}

\begin{tabular}{|c|c|c|c|}
\hline$\sqrt{\text { Підбір блоку }}$ & Створення системи & Створення додаткових елементів & Встановлення ливникової \\
\hline пресформи & виштовхувачів & системи центрування & втулки та кільця \\
\hline
\end{tabular}

Створення системи
охолодження

Рис. 1. Блок-схема послідовності процесу розроблення прес-форми

Раціональний поділ функцій під час автоматизованого проектування прес-форм між людиною та програмою - одна 3 найважливіших проблем, яку вирішують 3 використанням ЕОМ для автоматизації проектноконструкторських робіт. Залежно від проектованого об'єкта, ступеня можливої формалізації процесу його проектування, наявної технічної та програмної бази, проектну задачу можна реалізувати різними шляхами, але наявність розвиненого програмного забезпечення зовсім не гарантує спрощення процесу проектування до натискання кількох кнопок та відсутності потреби у кваліфікованому і креативному мисленні з боку інженеpa. Проте середовище для проектування Autodesk Inventor дає змогу максимально спростити процес розроблення оснащення і скоротити затрати часу.

Початковими даними для проектування прес-форми $є$ :

- креслення деталі з технічними вимогами та відомостями про їі призначення;

- матеріал, з якого виготовляють деталь, та його властивості (далеко не останню роль відіграють реологічні властивості пластмаси);

- технічні характеристики обладнання (термопластавтомата), на якому проводитимуть процес литва;

- інші технічні та технологічні фактори, які потрібно враховувати під час виконання проектних робіт.

У процесі проектування вибирають раціональні конструкції, проводять перевірки на міцність та розробляють робочі кресленики всіх деталей прес-форми, прогнозують потенційну якість деталі.

Система Autodesk Inventor дає змогу виконувати такі операції:

- створення параметризованої моделі деталі;

• вибір матеріалу деталі з власної бази даних;

- аналіз ухилів площин деталі;

- автоматичний підбір та створення ливників та ливникових каналів;

• обчислення усадки поверхонь деталі залежно від вибраного матеріалу;

- проектування блоків прес-форм: систем "колонка-втулка", пази у плитах та транспортні деталі за даними бібліотеки;

- проектування пуансонів;

• розрахунок конструктивних розмірів матриці;
• підбір та розміщення кріпильних елементів на складальному кресленику;

- проектування систем: фіксації, виштовхування та охолодження прес-форми;

- проектування додаткових деталей типу плит (підкладок: верхня та нижня, пуансонотримач);

- проектування хвостовиків;

- формування креслень (деталей блока, пакета та додаткових деталей);

- розрахунок маси;

- прогнозування якості деталі;

- формування специфікації та ряд інших функцій.

У сукупності всі ці функції надають конструктору необмежені можливості у плані створення деталей та оснащення. При цьому відпадає потреба у громіздких та надлишкових розрахунках, що потребують багато часу. Навіть дрібна помилка у подібних розрахунках може призвести до викривлення кінцевого результату, а це призводить до втрати часу та ресурсів, тому САПР на цей час дають уникнути подібних помилок, адже велика частина обчислень переноситься на машину. Окрім цього, велика база інженерних даних дає змогу підібрати оптимальні рішення для конкретних задач, що економить час.

Номенклатура деталей із пластмас, яку потрібно виготовити литвом у прес-форми під тиском на малих підприємствах може бути різноманітною, що потребує мінімальної тривалості підготовки виробництва для виготовлення виробу з відсутністю помилок і скороченням тривалості проектування, що може бути досягнуто з використанням САПР, але фактором, який стримує їх впровадження на підприємствах, $є$ висока вартість таких програмних продуктів. Отже, набір можливостей САПР для застосування на підприємстві має відповідати наявному типу виробництва, складності та номенклатурі виробів та обладнання і необхідності проведення розрахунків у процесі проектування для зменшення витрат на впровадження САПР та отримання результатів від їі використання за відносно короткий термін.

Процес проектування прес-форми розчленований на три етапи. На першому здійснюється створення або імпортування параметризованої 3D-моделі деталі (рис. 2), яку виливатимуть у прес-формі та їі всебічну перевірку 
на технологічність і відповідність усім технічним вимогам (рис. 3). Якщо у моделі немає помилок, то відбувається перехід до другого етапу - проектування самої прес-форми на базі уже готової моделі деталі, а за наявності помилок вносять відповідні корективи у початкові дані.

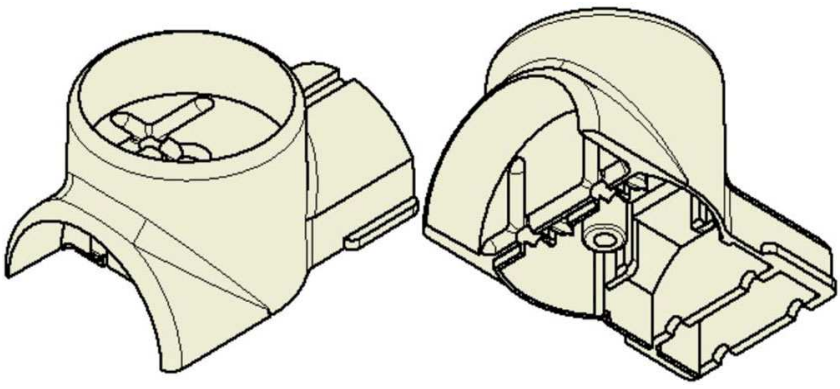

Рис. 2. 3D-модель деталі

Багато рутинних обчислень та підборів на другому етапі можна віддати самій системі Inventor (розрахунки усадок, раціональних температурних параметрів процесу лиття тощо). Проте це не означає, що для конструктора все зводиться до натискання кількох кнопок, адже він повинен провести підбір взаємного розміщення гнізд у прес-формі, типу та виду ливникової системи та системи охолодження тощо. Результатом другого етапу $\epsilon$ ряд графіків симуляції заливки деталей у прес-формі, прогноз якості кінцевого виливка (рис. 4) та модель блоку прес-форми у збірці (рис. 5), яку практично легко можна перетворити в кінцеві технологічні кресленики, а моделі окремих деталей використати як вихідні під час розроблення керівних програм для їх оброблення на верстатах з ЧПК.

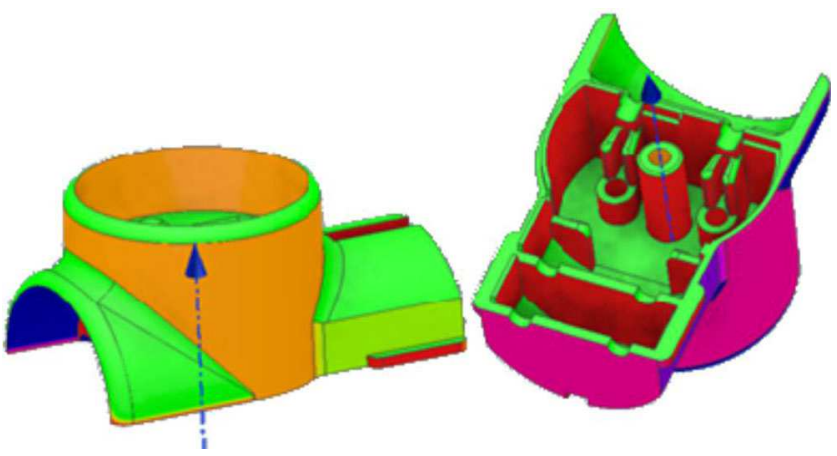

Рис. 3. Приклад виконання графічного аналізу ухилів: зелений та оранжевий кольори - раціональні кути нахилу; червоний чітко перпендикулярні поверхні

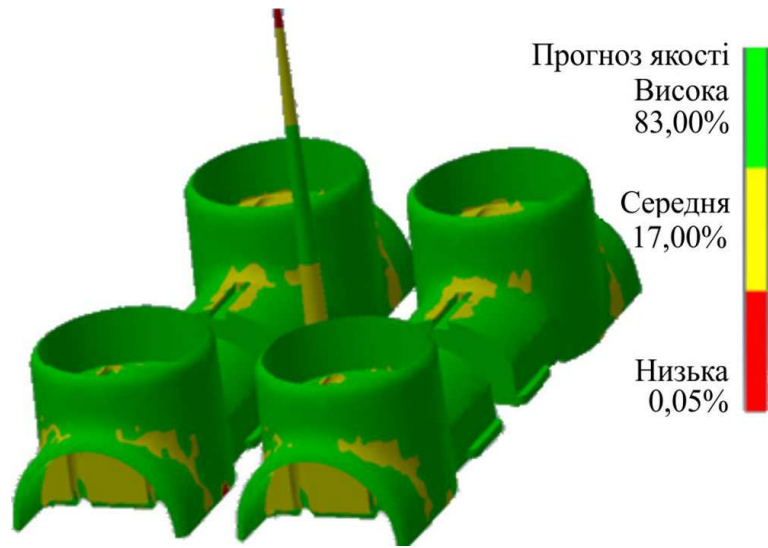

Рис. 4. Графік прогнозування якості виливка: зелений - висока; жовтий - середня; червоний - низька

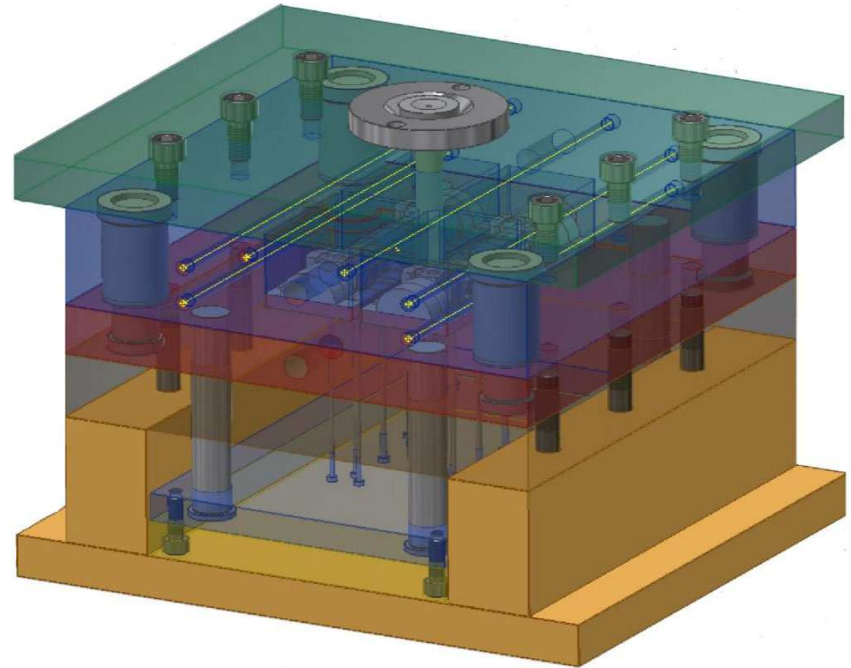

Рис. 5. Загальний вигляд готового блока прес-форми

Під час третього етапу проводять випробування раніше створених деталей прес-форми на міцність та стійкість. Достатньо завантажити деталь або певну збірку в середовище для випробування, створити новий експеримент і задати всі необхідні умови закріплення, взаємного розміщення та навантаження, які діють на модель. Система проведе обчислення всіх потрібних параметрів і видасть результати у формі графіків та таблиць. На рис. 6 показано напруження за Мізесом у матриці прес-форми.

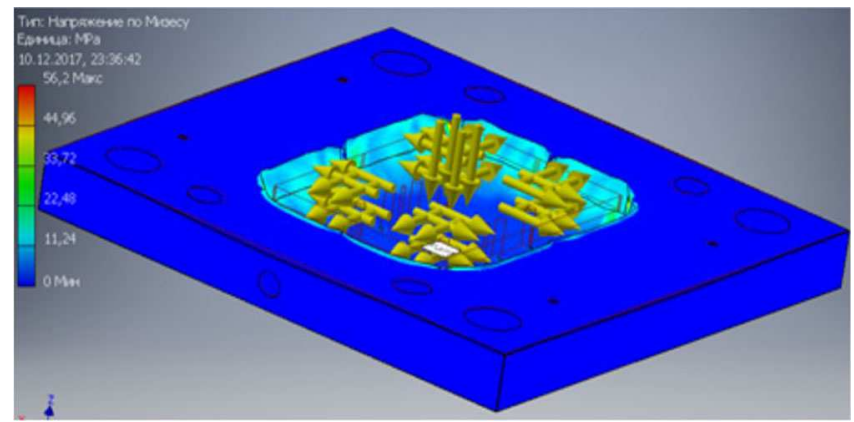

Рис. 6. Напруження за Мізесом у матриці

Висновки. Проектування прес-форми для лиття деталей зі складними поверхнями є складним і довготривалим процесом, від якості якого залежить подальше ііі виготовлення. Застосування сучасних програмних продуктів дає змогу спростити та істотно пришвидшити процеси: проектування прес-форми, здійснення аналізу ливарної порожнини та розроблення керівних програм для оброблення деталей на верстатах з ЧПК.

\section{Перелік використаних джерел}

Bekker, M. B., Zaslavskiy, M. L., \& Ignatenko, Yu. F. et al. (1990). Lite pod davleniem. (3rd ed.). Moscow: Mashinostroenie. 400 p. [In Russian].

Glinskih, A. (2002). Mirovoy ryinok CAD/CAM/CAE-sistem. Kompyuter-Inform, 01(117), 123-129. [In Russian].

Mazein, P. G., \& Shalamov, A. V. (2002). Skvoznoe avtomatizirovannoe proektirovanie $v$ CAD/CAM sistemah: uchebnoe posobie. Chelyabinsk: Izd-vo YuUrGU. 83 p. [In Russian].

Melloy, R. A., Braginskogo, V. A., Tsobkallo, E. S., \& Komarova, G. V. (Eds.) (2006). Konstruirovanie plastmassovyih izdeliy dlya litya pod davleniem. (Trans. from English). Saint Petersburg: Professiya. 512 p. [In Russian].

Mirzgoev, R. G., Braginskiy, V. A. et al. (1972). Osnovi konstruirovaniya $i$ rascheta detaley iz plastmass $i$ tehnologicheskoy osnastki dlya ih izgotovleniya. Leningrad, 416 p. [In Russian]. 
Norenkov, I. P. (2009). Osnovyi avtomatizirovannogo proektirovaniya: uchebnik dlya vuzov. (4th ed.). Moscow: Izd-vo MGTU im. N. E. Baumana. 430 p. [In Russian].

Ryibakov, A. V., Evdokimov, S. A., \& Meleshina, G. A. (2001). Sozdanie avtomatizirovannyih sistem $\mathrm{v}$ mashinostroenii: ucheb. posobie. Moscow: Izd-vo "Stankin". 157 p. [In Russian].
Suberlyak, O. V., \& Bashtannik, P. I. (2007). Tehnologiya pererobki polimernih ta kompozitsIynih materialiv: pidruchnyk dlya stud. VNZ. Lviv: Rastr-7. 375 p. [In Ukrainian].

Vidgof, N. B. (1979). Osnovyi konstruirovaniya litevyih form dlya termoplastov. Moscow: Mashinostroenie. 264 p. [In Russian].

Vlasov, S. V., Kandyirin, L. B., \& Kuleznev, V. N., et al. (2004). Osnovyi tehnologii pererabotki plastmass: uchebnik dlya vuzov. Moscow: Himiya. 600 p. [In Russian].

Р. Т. Карпик, С. В. Дидык

Ивано-Франковский национальный технический университет нефти и газа, г. Ивано-Франковск, Украина

Проведен анализ функций систем автоматизированного проектирования по критерию наличия в одном пакете возможностей: создавать деталь, проектировать форму для нее, проверять ее прочностные характеристики, симулировать заливки и прогнозировать качество конечной отливки. На основе анализа публикаций показано, что при использовании систем автоматизированного проектирования легче проводить стандартизацию и унификацию элементов технологической оснастки и систематизацию проектных решений, которые позволяют сократить сроки технологической подготовки производства и снизить себестоимость изделий. На основе созданной модели детали в среде Autodesk Inventor показан процесс разработки пресс-форм для литья с учетом технологических особенностей. Проведенная симуляция заливки с последующим прогнозом качества отливок дает возможность упростить и существенно ускорить процессы: проектирования пресс-формы, осуществления анализа литейной полости и разработки управляющих программ для обработки деталей на станках с ЧПУ. Проведены расчеты усадок, рациональных температурных параметров процесса литья и испытания созданных деталей прессформы на прочность и устойчивость с заданием условий закрепления, взаимного расположения и нагрузок, действующих на модель. В конечном итоге получена модель пресс-формы, из которой легко можно сделать конечные рабочие чертежи всех деталей.

Ключевые слова: системы автоматизированного проектирования; оснастка; механические напряжения; Autodesk Inventor; подготовка производства.

R. T. Karpyk, S. V. Didyk

Ivano-Frankivsk National Technical University of Oil and Gas, Ivano-Frankivsk, Ukraine

\section{AUTOMATION OF PROCESS OF DESIGNING PRESS FORMS FOR CASTING OF THERMOPLASTS UNDER PRESSURE}

The analysis of functions of automated designing systems is carried out on the criterion of availability in one package of possibilities: to create a part, to design a form for it, to check its strength characteristics, to simulate the pouring and to predict the quality of the final casting. On the basis of the publications analysis it is shown that when using automated design systems, it is easier to standardize and unify the elements of technological equipment and systematize design decisions, which in turn allow shortening the terms of technological preparation of production and reduce the cost price of products. In the process of preparing the industry to reduce the cost of introducing automated design systems and obtaining results from their use in a relatively short period of time, it is necessary to choose the software products taking into account the existing production type, the complexity, the nomenclature of products and equipment, and the need for calculations, due to their high cost. The list of functions of the Autodesk Inventor System, which can be used in designing molds, without carrying out cumbersome and excessive calculations, which takes a long time and when mistakes are made in which the mold will not perform its functional purpose, which entails a loss of time and resources, is given on re-manufacturing of defective parts. On the basis of the created model parts in the environment of Autodesk Inventor shows the process of developing molds for casting, taking into account technological features. A simulation of pouring with the subsequent prediction of the quality of castings has been performed, which simplifies and significantly accelerates processes such as mold design, analysis of foundry cavity and the development of control programs for the processing of details on CNC machines. The calculations of shrinkage, rational temperature parameters of the molding process and testing of the created parts of the mold for durability and stability with specification of conditions of fastening, mutual placement and loading acting on the model are carried out. In the final result, a model of mold is obtained, from which it is easy to make final work shafts of all parts.

Keywords: automated design systems; equipment; mechanical stresses; Autodesk Inventor; preparation of production. 